\title{
Prophylactic cranial irradiation in 399 patients with limited-stage small cell lung cancer
}

\author{
GUOQIN QIU, XIANGHUI DU, XIA ZHOU, WUAN BAO, LEI CHEN, \\ JIANXIANG CHEN, YONGLING JI and SHENGYE WANG
}

Department of Radiation Oncology, Zhejiang Cancer Hospital, Hangzhou, Zhejiang 310022, P.R. China

Received February 15, 2015; Accepted January 19, 2016

DOI: $10.3892 / \mathrm{ol} .2016 .4231$

\begin{abstract}
The benefit of prophylactic cranial irradiation (PCI) in limited-stage small-cell lung cancer (LS-SCLC) was established in a meta-analysis performed in 1999. Since then, considerable progress has been made in the diagnosis, staging and treatment of LS-SCLC, including chemotherapy and radiotherapy, which led to a longer survival time in patients. Therefore, the magnitude of the benefit of PCI should be re-evaluated. Furthermore, the optimum timing of PCI for LS-SCLC treatment has not been established and more data is required to demonstrate this. In the present retrospective study, the cases of patients that were diagnosed with LS-SCLC between March 2005 and December 2010 were reviewed. The main eligibility criteria of patients were a diagnosis of LS-SCLC and the achievement of a complete response (CR) or near CR subsequent to receiving $\geq 3$ cycles of cisplatin-based chemotherapy, with or without advanced thoracic radiotherapy. Early and late PCI groups were separated using the median time interval between the start of primary chemotherapy and the start of PCI. In total, 80 patients were excluded from the analysis, including 9 patients that developed brain metastases, 2 during primary chemotherapy and 7 during radiotherapy. The remaining 399 patients were deemed eligible. PCI was administered to 185 patients; 92 patients were in the early PCI group and 93 were in the late PCI group. PCI significantly decreased the incidence of brain metastases $[\mathrm{P}<0.001 ; \mathrm{HR}$, 0.24 ; $95 \%$ confidence interval (CI), 0.15-0.39] and improved the overall survival time of the patients (median survival time, 21.5-38.8 months; $\mathrm{P}<0.001$; HR, 0.60; 95\% CI, 0.45-0.79). However, no significant difference was identified between the early and late PCI groups, either in the incidence of brain metastases $(\mathrm{P}=0.875)$ or the overall survival time $(\mathrm{P}=0.361)$. Multivariate analysis revealed that PCI $(\mathrm{P}=0.004)$ and thoracic
\end{abstract}

Correspondence to: Dr Guoqin Qiu, Department of Radiation Oncology, Zhejiang Cancer Hospital, 38 Guangji Road, Hangzhou, Zhejiang 310022, P.R. China

E-mail: qiuguoqinaaa@126.com

Key words: limited-stage small cell lung cancer, prophylactic cranial irradiation, brain metastases, overall survival radiotherapy $(\mathrm{P}=0.023)$ were the only 2 independent favorable prognostic factors of overall survival time. The present study demonstrates that PCI may be of considerable benefit to increase the survival rate and time of patients, and early PCI is as effective as late PCI. However, the present study recommends that PCI should be offered as soon as primary chemotherapy is completed, since there is a greater risk of developing brain metastases during thoracic radiotherapy.

\section{Introduction}

Small-cell lung cancer (SCLC) accounts for $15-20 \%$ of all types of lung cancers (1). SCLC is characterized by a high incidence of metastatic disease when patients initially present with SCLC, and a high treatment response rate. Limited stage-SCLC (LS-SCLC) is diagnosed in 30-40\% of patients with SCLC.

The first-line treatment for patients with LS-SCLC is cisplatin-based chemotherapy combined with irradiation of the chest region $(2,3)$, which yields a complete response (CR) rate of $50-85 \%$, a median duration of survival of 12-20 months, and a two-year disease-free survival rate of $15-40 \%$. In addition, the risk of thoracic recurrence decreases with combined treatment; however, brain metastasis becomes one of the main types of relapse (2). The cumulative incidence of brain metastasis two years post-treatment is $45-58 \%$ in patients that receive combined treatment $(4,5)$.

Prophylactic cranial irradiation (PCI) has been demonstrated to reduce the risk of brain metastases from 58.6 to $33.3 \% 3$ years subsequent to combined therapy, and in addition, meta-analyses have revealed that PCI results in a $16 \%$ reduction in mortality rate, which modestly increases the 3-year survival rate between 15.3 and $20.7 \%$. (6). However, in recent years, there has been a more effective systemic chemotherapy treatment (etoposide regimen and cisplatin-combination regimens) that has been combined with more advanced thoracic radiotherapy, including three-dimensional conformal and intensity-modulated radiation therapy $(7,8)$; therefore, the magnitude of benefit from PCI should be re-evalauated.

The benefit of PCI has been determined, but the optimal timing of PCI intervention has not been examined (6). Auperin et al demonstrated by meta-analysis that PCI had a significantly greater effect on the incidence of brain metastasis in patients that received PCI within 6 months following 
induction therapy compared with patients that received PCI after 6 months $(\mathrm{P}=0.01)(6)$. However, the results from Auperin et al were from a subgroup analysis and should be interpreted with caution. Two prospective randomized studies comparing the optimal timing of PCI revealed conflicting conclusions; an early randomized study revealed no difference in the frequency of brain metastases between PCI performed at the start of induction treatment and PCI delivered 6 weeks later, whereas a later study demonstrated a statistically significant decrease in intracranial recurrence when PCI was performed during chemoradiotherapy as opposed to following chemoradiotherapy $(9,10)$. Therefore, the optimal timing of PCI delivery should be established. The aim of the present study was to re-evaluate the benefits of PCI and investigate whether a delay in delivering PCI following the start of the first chemotherapy cycle leads to a detrimental outcome of patients.

\section{Materials and methods}

Patients. Histological or cytological evidence of the presence of SCLC was required. The selected patients were diagnosed with LS-SCLC and had achieved CR or near CR subsequent to primary chemotherapy or chemoradiotherapy. Patients underwent a staging evaluation prior to the initiation of chemotherapy. The staging evaluation consisted of a computed tomography (CT) scan of the chest, ultrasonography of the neck and upper abdomen, magnetic resonance imaging (MRI) or CT of the head, a radionuclide bone scan, and a CT scan of the upper abdomen. Radiographs of the regions of increased radionuclide uptake were confirmed by $\mathrm{CT}$ or MRI. A bone marrow biopsy was not used for staging. Lymph nodes that were suspected of being enlarged were observed using ultrasonography and confirmed by cytology using a needle aspirate.

LS-SCLC was defined as cancer limited to one hemithorax, the mediastinum and supraclavicular nodes, provided that all volumes were combined in the same radiotherapy field as the primary tumor.

Patients were excluded from analysis for the following reasons: Cytological evidence of a malignant pleural effusion; the presence of a second malignancy; $\leq 2$ cycles of primary chemotherapy undertaken; the presence of squamous cell carcinoma or adenocarcinoma; and the presence of progressive disease during chemo- or radiotherapy.

The present study was approved by the Medical Ethics Committee of Zhejiang Cancer Hospital (Hangzhou, China; approval no., IRB-2016-10).

Treatment strategy. In total, $\geq 3$ cycles of cisplatin-based treatment regimens were administered to patients. Chemotherapy regimens mainly consisted of etoposide and cisplatin therapy (cisplatin, $25 \mathrm{mg} / \mathrm{m}^{2}$ on days 1-3 or carboplatin, area under the curve-based dosing of 5 on day 1 , and etoposide, $80-100 \mathrm{mg} / \mathrm{m}^{2}$ on days 1-3). Thoracic radiotherapy (TRT) was performed concurrently, sequentially or alternatively with chemotherapy. TRT was administered with 3-dimensional conformal radiotherapy (CRT) or intensity-modulated radiotherapy technique, and the prescription dose was 40-66 Gy in 20-33 fractions. The target volume consisted of all gross disease, the ipsilateral hilum and the entire mediastinum. The supraclavicular fossa was not irradiated routinely if there were no enlarged lymph nodes in those sites.

The patients received whole-brain PCI, in which 4-6 MV photons were delivered with opposed lateral portals, with normal tissue sparing of the lens. The irradiation fields included a $\geq 1 \mathrm{~cm}$ margin on the calvarium. PCI was performed within 1 month following primary chemotherapy or chemoradiotherapy.

To investigate the impact of the timing of PCI on prognosis, early and late PCI groups were established from the median time between the start of primary chemotherapy and the initiation of PCI.

Response assessment and follow-up. The response assessment at the end of primary chemotherapy or chemo- and radiotherapy was based on the results of a CT scan of the chest and upper abdomen, an MRI of the head and a radionuclide bone scan. Fiberoptic bronchoscopy was not performed. CR was defined as the disappearance of all target lesions. Partial response (PR) was defined as a decrease of $\geq 50 \%$ in the greatest dimensions of target tumors, using the sum at baseline as a reference. Near CR was defined as a continuum between CR and PR.

CT of the chest and ultrasonography of the neck and upper abdomen were repeated every 3 months for 2 years following the end of treatment, and every 6 months thereafter. An MRI of the head was used if the patients presented with a headache or neurological symptoms suggestive of brain metastases.

Endpoints. The primary endpoint was the cumulative incidence of brain metastases. Overall survival (OS) time was the secondary endpoint and was defined as the duration between the date of the first chemotherapy cycle and the date of mortality from any cause or the last known date that the patient was alive.

Statistical analysis. All data were calculated using SPSS software version 13.0 (SPSS Inc., Chicago, IL, USA). The differences within each categorical variable were assessed using $\chi^{2}$ tests. The Kaplan-Meier estimate was used to calculate brain metastasis rates. Survival time was calculated as the time elapsed between the date of primary chemotherapy and the date of mortality. The patients that remained alive were censored at the date they were last known to be alive. The Kaplan-Meier estimate was used to calculate survival time curves and the Mantel-Cox version of the log rank test was used to determine associations between OS time and clinical factors, including the age at diagnosis, gender, smoking status, Eastern Cooperative Oncology Group performance score (ECOG PS), weight loss, thoracic radiotherapy and PCI. Cox's proportional hazards model, with a backward-forward, stepwise method, was used to identify significant variables. $\mathrm{P}<0.05$ was considered to indicate a statistically significant difference.

\section{Results}

Patient characteristics. Between March 2005 and December 2010, 479 patients with LS-SCLC were treated at Zhejiang Cancer Hospital (Hangzhou, Zhejiang, China). In total, 399 patients were eligible for the present study, and 80 patients 
Table I. Characteristics of 399 patients with limited stage-small cell lung cancer.

\begin{tabular}{|c|c|c|c|c|}
\hline \multirow[b]{2}{*}{ Characteristic } & \multicolumn{3}{|c|}{ Group, n (\%) } & \multirow[b]{2}{*}{ P-value } \\
\hline & No PCI & Early PCI & Late PCI & \\
\hline Total & $214(100.0)$ & $92(100.0)$ & $93(100.0)$ & \\
\hline \multicolumn{5}{|l|}{ Age } \\
\hline$<65$ years & $176(82.2)$ & $83(90.2)$ & $85(91.4)$ & \multirow[t]{2}{*}{0.045} \\
\hline$\geq 65$ years & $38(17.8)$ & $9(9.8)$ & $8(8.6)$ & \\
\hline \multicolumn{5}{|l|}{ Gender } \\
\hline Male & $178(83.2)$ & $72(78.3)$ & $72(77.4)$ & \multirow[t]{2}{*}{0.399} \\
\hline Female & $36(16.8)$ & $20(21.7)$ & $21(22.6)$ & \\
\hline \multicolumn{5}{|l|}{ ECOG PS } \\
\hline $0-1$ & $208(97.2)$ & $90(97.8)$ & $91(97.8)$ & \multirow[t]{2}{*}{0.920} \\
\hline 2 & $6(2.8)$ & $2(2.2)$ & $2(2.2)$ & \\
\hline \multicolumn{5}{|l|}{ Weight loss } \\
\hline$<5$ & $202(94.4)$ & 87 (94.6) & $88(94.6)$ & \multirow[t]{2}{*}{0.996} \\
\hline$\geq 5$ & $12(5.6)$ & $5(5.4)$ & $5(5.4)$ & \\
\hline \multicolumn{5}{|l|}{ Smoking status } \\
\hline Yes & $164(76.6)$ & $64(70.0)$ & $66(71.0)$ & \multirow[t]{2}{*}{0.346} \\
\hline No & $50(23.4)$ & $28(30.0)$ & $27(29.0)$ & \\
\hline \multicolumn{5}{|l|}{ TRT } \\
\hline Yes & $167(78.0)$ & $85(92.4)$ & 92 (98.9) & \multirow[t]{2}{*}{0.000} \\
\hline No & $47(22.0)$ & $7(7.6)$ & $1(1.1)$ & \\
\hline \multicolumn{5}{|l|}{ CT cycles } \\
\hline 3 & $12(5.6)$ & $4(4.4)$ & $3(3.2)$ & \multirow[t]{3}{*}{0.128} \\
\hline $4-6$ & $198(92.5)$ & $88(95.6)$ & $85(91.4)$ & \\
\hline $7-8$ & $4(1.9)$ & $0(0.0)$ & $5(5.4)$ & \\
\hline
\end{tabular}

PCI, prophylactic cranial irradiation; ECOG PS, Eastern Cooperative Oncology Group performance score; TRT, thoracic radiotherapy; CT, chemotherapy.

were excluded from the analysis as follows: 22 patients underwent $\leq 2$ cycles of the first chemotherapy regimen; 2 patients possessed mixed carcinoma; 46 patients did not achieve CR or near CR following first-line treatment; and 10 patients demonstrated progressive disease during chemo- or radiotherapy, of whom 9 patients developed brain metastases, with 7 developing metastases during thoracic radiotherapy and 2 developing metastases during chemotherapy, and 1 patient developed liver metastases during chemotherapy. The median follow-up time was 26.5 months (range, 3.1-77.4 months).

Of the 399 patients whose records were examined, the median age was 55 years (range, 25-79 years) and $81 \%$ of the patients were men. In total, $98 \%$ of the patients possessed an ECOG PS of 0 or 1 at baseline, and 25 patients underwent thoracic surgery and 344 patients received thoracic radiotherapy. The mean dose of thoracic radiotherapy was 54.10 \pm 0.43 Gy.

PCI was administered to 185 patients. The mean PCI dose was $28.22 \pm 0.30 \mathrm{~Gy}$ in 10 fractions. In $98 \%$ of patients, PCI was delivered subsequent to the end of primary chemotherapy or chemoradiotherapy. The median interval between the start of primary chemotherapy and the start of PCI was 6 months. In total, 92 patients received early PCI and 93 patients received late PCI. The median interval between the start of primary chemotherapy and the initiation of PCI was 5.0 months (range, 1.5-6.0 months) in the early PCI group and 7.2 months (range, 6.1-16.9 months) in the late PCI group. In total, 214 patients did not receive PCI due to the individual preference of the physician or the patient.

The baseline characteristics of the patients are presented in Table I. There were no differences in the distribution of the majority of characteristics between the PCI group and the group that did not receive PCI, with the exception of age and the number of patients that underwent thoracic radiotherapy. An increased number of patients received thoracic radiotherapy in the PCI group compared to the group that did not receive PCI $(\mathrm{P}<0.001)$. Patients $>65$ years of age were significantly less likely to receive PCI compared with patients aged $<65$ years $(\mathrm{P}=0.045)$. The baseline characteristics were similar between the early and late PCI groups.

Cumulative incidence of brain metastases. Symptomatic brain metastases were identified in 75 of the 215 patients in the group that did not receive PCI $(34.9 \%)$ and in 21 of the 185 patients in the PCI group $(11.4 \%$; $\mathrm{P}<0.001)$. The median time between the start of primary chemotherapy and the incidence of brain 
Table II. Univariate analysis of the prognostic factors for survival rate in patients with limited-stage small-cell lung cancer.

\begin{tabular}{|c|c|c|c|c|}
\hline \multirow[b]{2}{*}{ Characteristic } & \multirow[b]{2}{*}{ MST, months } & \multicolumn{2}{|c|}{ OS rate, $\%$} & \multirow[b]{2}{*}{$\mathrm{P}$-value } \\
\hline & & 1-Year & 3-Year & \\
\hline \multicolumn{5}{|l|}{ Age } \\
\hline$<65$ years & 28.1 & 88 & 44 & 0.111 \\
\hline$\geq 65$ years & 22.4 & 90 & 32 & \\
\hline \multicolumn{5}{|l|}{ Gender } \\
\hline Male & 26.4 & 88 & 41 & 0.087 \\
\hline Female & 38.5 & 92 & 52 & \\
\hline \multicolumn{5}{|l|}{ ECOG PS } \\
\hline $0-1$ & 28.1 & 89 & 43 & 0.427 \\
\hline 2 & 22.4 & 80 & 33 & \\
\hline \multicolumn{5}{|l|}{ Weight loss } \\
\hline$<5$ & 27.4 & 89 & 43 & 0.948 \\
\hline$\geq 5$ & 34.4 & 73 & 44 & \\
\hline \multicolumn{5}{|l|}{ Smoking status } \\
\hline Yes & 26.1 & 87 & 40 & 0.027 \\
\hline No & 38.5 & 92 & 51 & \\
\hline \multicolumn{5}{|l|}{ TRT } \\
\hline Yes & 30.2 & 90 & 46 & 0.001 \\
\hline No & 19.1 & 78 & 25 & \\
\hline \multicolumn{5}{|l|}{ CT cycles } \\
\hline$<4$ & 25.1 & 79 & 48 & 0.601 \\
\hline$\geq 4$ & 27.5 & 89 & 43 & \\
\hline \multicolumn{5}{|l|}{ PCI } \\
\hline Yes & 38.8 & 96 & 53 & 0.000 \\
\hline No & 21.5 & 82 & 35 & \\
\hline \multicolumn{5}{|l|}{ Timing of PCI } \\
\hline Early PCI & 32.6 & 92 & 50 & 0.361 \\
\hline Late PCI & 40.9 & 99 & 55 & \\
\hline
\end{tabular}

OS, overall survival; MST, median survival time; ECOG PS, Eastern Cooperative Oncology Group performance score; TRT, thoracic radiotherapy; CT, chemotherapy; PCI, prophylactic cranial irradiation.

metastases was 10.6 months (range, 2.5-46.0 months). The cumulative incidence curves are revealed in Fig. 1A. The cumulative risks of symptomatic brain metastases at 6,12 and 24 months were 7,29 and $42 \%$ in the group that did not receive PCI, and 0, 3 and $13 \%$ in the PCI group. The hazards ratio for the PCI group was 0.24 [95\% confidence interval (CI), 0.15-0.39]. There was no significant difference between the early PCI and late PCI groups $(\mathrm{P}=0.875)$; however, there was an increasing trend in the incidence of brain metastases in the late PCI group 3 years subsequent to receiving PCI (Fig. 1B).

Overall survival $(O S)$ rate and time. The median survival time was 27.5 months and the OS rates at 1 and 3 -years were 89 and $43 \%$, respectively, for the entire cohort of patients. The survival outcomes are shown in Fig. 2A and B. In the group that did not receive PCI, the median survival time was 21.5 months, and the 1 and 3-year OS rates were 82 and 35\%, respectively. In the PCI group, the median survival time was 38.8 months, and the 1 and 3-year OS rates were 96 and 53\%, respectively, $(\mathrm{P}<0.001$; HR, 0.60; 95\% CI, 0.45-0.79). In the early PCI group, the median survival time was 32.6 months, and the 1 and 3-year OS rates were 92 and 50\%, respectively. In the late PCI group, the median survival time was 40.9 months, and the 1 and 3-year OS rates were 99 and 55\%, respectively $(\mathrm{P}=0.361)$.

Patient and clinical characteristics were evaluated to determine their prognostic value in terms of OS rate in Table II. In total, 9 characteristics (age, gender, ECOG PS, weight loss, smoking status, thoracic radiotherapy, PCI, the number of chemotherapy cycles and the timing of PCI) were analyzed. Univariate analysis demonstrated that age, gender, ECOG PS, weight loss, the number of chemotherapy cycles and the timing of PCI were not significantly associated with the survival rate; however, smoking status, PCI and thoracic radiotherapy were significant prognostic factors for the survival time. As revealed in Table III, multivariate analysis demonstrated that PCI $(\mathrm{P}=0.004)$ and thoracic radiotherapy $(\mathrm{P}=0.023)$ were the only 2 independent favorable prognostic factors of OS rate. Smoking status demonstrated a marginally significant effect on the $\mathrm{OS}$ rate $(\mathrm{P}=0.051)$.

\section{Discussion}

Following an individual patient data-based meta-analysis, published in 1999, PCI became the standard treatment in patients with LS-SCLC that achieved complete remission subsequent to chemotherapy and radiotherapy (6). However, in the present retrospective study, $>50 \%$ of patients with LS-SCLC did not receive PCI. There is a significant discrepancy between the recommended evidence-based optimum rate of radiotherapy in lung cancer and the actual rate used in patients, since PCI is recommended for all patients (6), but not all patients receive it, which suggests that recommending PCI remains controversial among doctors and patients (11). In addition, in the present study, elderly patients were less likely to receive PCI compared with younger patients, indicating that doctors and patients were more cautious in delivering PCI to elderly patients, due to PCI potentially causing chronic neurotoxicity (12-14). Consequently, studies are required to demonstrate whether PCI is safe and effective in elderly individuals.

The present retrospective study evaluated PCI in 399 patients with LS-SCLC that achieved CR or near CR following primary chemo- or radiotherapy and demonstrated that PCI resulted in a significant decrease in the rate of brain metastases ( $\mathrm{P}<0.001$; HR, 0.24; 95\% CI, 0.15-0.39) and a significant improvement in the OS rate $(\mathrm{P}<0.001$; HR, 0.60; 95\% CI, 0.45-0.79). PCI remained a significant factor following adjustment for age, gender, ECOG PS, weight loss, smoking status, thoracic radiotherapy and the number of chemotherapy cycles (HR, 0.655; $\mathrm{P}=0.004)$. These favorable survival rate results were consistent with other studies that evaluated PCI in patients with LS-SCLC $(6,15,16)$. Notably, in the present study the PCI group and the group that did not receive PCI possessed a longer median survival time compared with 
Table III. Multivariate analysis of the prognostic factors for survival rate in patients with limited-stage small-cell lung cancer.

\begin{tabular}{|c|c|c|c|c|c|}
\hline Characteristic & B & HR & $95 \% \mathrm{CI}$ & $\chi^{2}$ & $\mathrm{P}$-value \\
\hline Age, years $(\geq 65$ vs. $<65)$ & 0.097 & 1.101 & $0.908-1.336$ & 0.956 & 0.328 \\
\hline Gender (female vs. male) & -0.096 & 0.908 & $0.542-1.522$ & 0.133 & 0.715 \\
\hline ECOG PS (2 vs. 0-1) & 0.300 & 1.349 & $0.587-3.100$ & 0.498 & 0.480 \\
\hline Weight loss ( $\geq 5$ vs. $<5 \%$ ) & -0.066 & 0.936 & $0.512-1.709$ & 0.047 & 0.829 \\
\hline Smoking status (yes vs. no) & 0.329 & 1.390 & $0.999-1.934$ & 3.816 & 0.051 \\
\hline TRT (yes vs. no) & -0.413 & 0.661 & $0.463-0.945$ & 5.163 & 0.023 \\
\hline CT cycles $(\geq 4$ vs. $<4)$ & -0.056 & 0.945 & $0.507-1.763$ & 0.031 & 0.860 \\
\hline PCI (yes vs. no) & -0.423 & 0.655 & $0.491-0.873$ & 8.337 & 0.004 \\
\hline
\end{tabular}

B, coefficient B; HR, hazard ratio; CI, confidence interval; ECOG PS, Eastern Cooperative Oncology Group performance score; TRT, thoracic radiotherapy; $\mathrm{CT}$, chemotherapy; $\mathrm{PCI}$, prophylactic cranial irradiation.
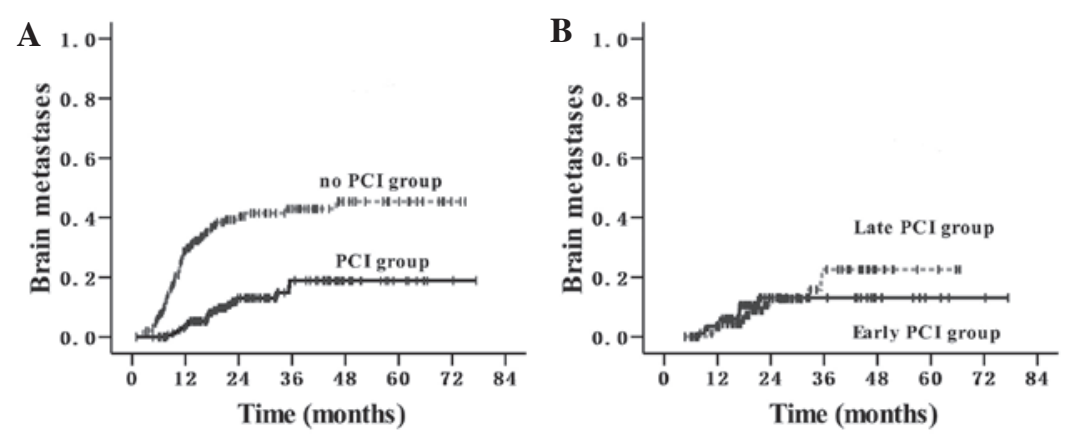

Figure 1. Cumulative incidence of symptomatic brain metastases. (A) PCI group vs. no PCI group ( $\mathrm{P}<0.001$; hazard ratio, 0.24 ; $95 \%$ confidence interval, 0.15-0.39). (B) Early PCI group vs. late PCI group ( $\mathrm{P}=0.875)$. PCI, prophylactic cranial irradiation.
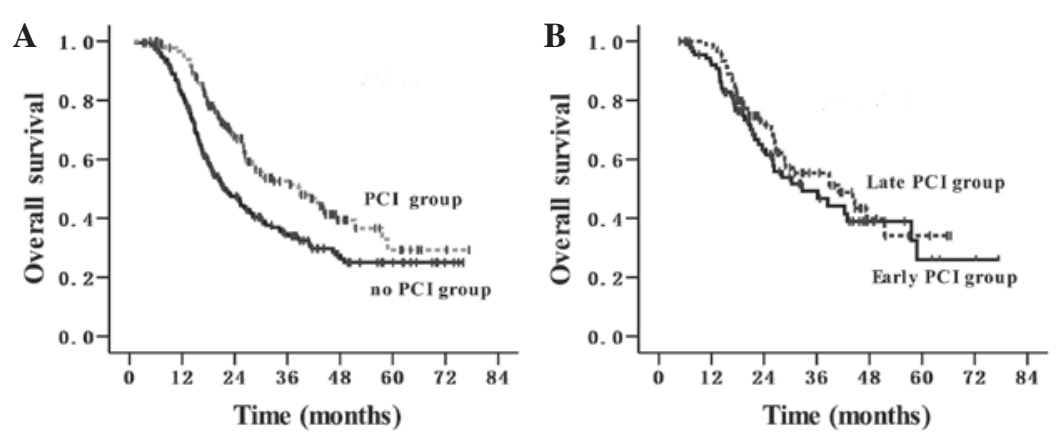

Figure 2. Overall survival time. (A) PCI group vs. no PCI group (38.8 vs. 21.5 months; $\mathrm{P}<0.001$; hazard ratio, 0.60; 95\% confidence interval, 0.45-0.79). (B) Early PCI group vs. late PCI group $(\mathrm{P}=0.361)$. PCI, prophylactic cranial irradiation.

other studies (17-19). The magnitude of benefit from PCI in the present study increased the 3-year survival rate between 35 and $53 \%$ and increased the median survival time between 21.5 and 38.8 months, which was greater than that revealed in other studies $(6,12,16)$. The present study hypothesizes that this variation is partly due to the improved accuracy of the diagnostic staging and cisplatin-based chemotherapy combined with the advanced radiotherapy technology used in the present study, which resulted in an improved control rate of intrathoracic diseases (20). Early retrospective data also suggested that the role of PCI was largely dependent on the response of the primary tumor to CRT (21). In addition, the current study demonstrated that $90 \%$ of brain metastases appeared within the first 2 years of induction chemotherapy, which was consistent with other studies $(5,11,17)$.

Despite the disadvantages of a retrospective analysis, the present study demonstrates the advantage that all results were acquired from a patient cohort that was treated in a major hospital over several years. The present retrospective study demonstrated that the timing of PCI initiation was not significantly associated with the incidence of brain metastases and the OS rate or time. The baseline characteristics were similar between the early and late PCI groups; therefore, this result was not confounded by other clinical factors. 
It is well established that early chest radiotherapy may improve the survival rate of patients with LS-SCLC (22). As a prophylactic treatment, it is unknown whether early PCI may be as effective as early chest radiotherapy. A phase II study revealed that the incidence of brain metastasis was $7.3 \%$ in the early PCI group, when PCI was performed during chemoradiotherapy, and $20 \%$ in the late PCI group, when PCI was performed following chemoradiotherapy $(\mathrm{P}=0.00901)$. Consequently, the timing of PCI was hypothesized to be an important factor for decreasing the incidence of brain metastases (10). However, the increased risk of long-term neurotoxicity should be considered when PCI is used concurrently with chemotherapy (23-25). In the present study, 98\% of patients received PCI following the end of primary chemoradiotherapy, and hyperfractionated accelerated radiotherapy was not used; therefore, the median interval between the start of primary chemotherapy and the initiation of PCI was as long as 6 months. This was similar to the interval time in the meta-analysis by Auperin et al, demonstrating that the interval has no effect on the risk of mortality of patients (6).

The present findings are also consistent with two additional studies $(23,24)$. In a retrospective study, which assessed 118 patients that received PCI, the risk of developing cerebral recurrence was not observed to be significantly different between patients that received PCI 2-5 months subsequent to diagnosis and those that received it 5-15 months subsequent to diagnosis $(\mathrm{P}=0.26)(26)$. A pooled analysis on 421 patients with LS-SCLC also revealed that the length of the interval between the start of chemotherapy and the initiation of $\mathrm{PCI}$ did not affect subsequent survival rates (HR, 1.00; 95\% CI, 0.99-1.01; $\mathrm{P}=0.58)(27)$. However, the present results should be interpreted with caution, since 9 patients were excluded from the primary analysis for developing brain metastases during primary chemoradiotherapy, with 2 patients developing metastases during chemotherapy and 7 patients developing metastases during thoracic radiotherapy, which was administered sequentially with chemotherapy. The brain was previously considered as a pharmacological sanctuary where metastases could develop, due to the protection provided by the blood-brain barrier (BBB). However, in recent decades, it has become clear that the BBB is disrupted in metastatic tumor tissue, rendering it permeable to pharmacological agents, including CPT-11 and cisplatin (28). This is additionally confirmed in the present observations that intracranial progression is relatively rare during primary chemotherapy. The present finding that 7 patients developed brain metastases during thoracic radiotherapy suggests that PCI should be administered as soon as primary chemotherapy is completed.

The present study has several limitations. First, it is a single-institution, retrospective review. The present study attempted to limit the bias inherent in comparing two non-randomized groups; however, it is likely that there are other clinical factors that may have contributed to the difference in the OS time and rate between the groups, including the dose and different schedules of radiotherapy, chemotherapy combination and the different treatment options provided during the development of cancer. In addition, the latest edition of the tumor-node-metastasis staging system was not used in the present survival rate and time analysis (29). Second, the follow-up time of the present study was relatively short. In total, 73 patients were followed-up for $\leq 24$ months and symptomatic brain metastases may not have been detected in such a short follow-up period. Third, the cut-off time of 6 months set in the present study for the early and late PCI groups may not be optimal.

In conclusion, the present study identified that PCI significantly decreased the incidence of brain metastases and improved the overall survival rate in patients with LS-SCLC. Early PCI administered within 6 months of the start of first-line chemotherapy was as effective as late PCI, which was PCI that was administered 6 months later. However, it is recommended that PCI should be administered to patients as soon as first-line chemotherapy is completed.

\section{Acknowledgements}

The authors are grateful to all the physicians and patients for their co-operation in the present study.

\section{References}

1. Govindan R, Page N, Morgensztern D, Read W, Tierney R, Vlahiotis A, Spitznagel EL and Piccirillo J: Changing epidemiology of small-cell lung cancer in the United States over the last 30 years: analysis of the surveillance, epidemiologic, and end results database. J Clin Oncol 24: 4539-4544, 2006.

2. Pignon JP, Arriagada R, Ihde DC, Johnson DH, Perry MC, Souhami RL, Brodin O, Joss RA, Kies MS, Lebeau B, et al: A meta-analysis of thoracic radiotherapy for small-cell lung cancer. N Engl J Med 327: 1618-1624, 1992.

3. Warde P and Payne D: Does thoracic irradiation improve survival and local control in limited-stage small-cell carcinoma of the lung? A meta-analysis. J Clin Oncol 10: 890-895, 1992.

4. Komaki R, Cox JD and Whitson W: Risk of brain metastasis from small cell carcinoma of the lung related to length of survival and prophylactic irradiation. Cancer Treat Rep 65: 811-814, 1981.

5. Arriagada R, Le Chevalier T, Borie F, Rivière A, Chomy P, Monnet I, Tardivon A, Viader F, Tarayre M and Benhamou S: Prophylactic cranial irradiation for patients with small-cell lung cancer in complete remission. J Natl Cancer Inst 87: 183-190, 1995.

6. Aupérin A, Arriagada R, Pignon JP, Le Péchoux C, Gregor A, Stephens RJ, Kristjansen PE, Johnson BE, Ueoka H, Wagner H and Aisner J; Prophylactic Cranial Irradiation Overview Collaborative Group: Prophylactic cranial irradiation for patients with small-cell lung cancer in complete remission. N Engl J Med 341: 476-484, 1999.

7. Sundstrøm S, Bremnes RM, Kaasa S, Aasebø U, Hatlevoll R, Dahle R, Boye N, Wang M, Vigander T, Vilsvik J, et al; Norwegian Lung Cancer Study Group: Cisplatin and etoposide regimen is superior to cyclophosphamide, epirubicin, and vincristine regimen in small-cell lung cancer: Results from a randomized phase III trial with 5 years' follow-up. J Clin Oncol 20: 4665-4672, 2002.

8. Pujol JL, Carestia L, Daurès JP: Is there a case for cisplatin in the treatment of small-cell lung cancer? A meta-analysis of randomized trials of a cisplatincontaining regimen versus a regimen without this alkylating agent. Br J Cancer 83: 8-15, 2000.

9. Perez CA, Krauss S, Bartolucci AA, Durant JR, Lowenbraun S, Salter MM, Storaalsi J, Kellermeyer R and Comas F: Thoracic and elective brain irradiation with concomitant or delayed multiagent chemotherapy in the treatment of localized small cell carcinoma of the lung: A randomized prospective study by the Southeastern Cancer Study Group. Cancer 47: 2407-2413, 1981.

10. Sas-Korczyńska B, Korzeniowski S and Wójcik E: Comparison of the effectiveness of "late" and "early" prophylactic cranial irradiation in patients with limited-stage small cell lung cancer. Strahlenther Onkol 186: 315-319, 2010.

11. Delaney G, Barton M, Jacob S and Jalaludin B: A model for decision making for the use of radiotherapy in lung cancer. Lancet Oncol 4: 120-128, 2003. 
12. Giuliani M, Sun A, Bezjak A, Ma C, Le LW, Brade A, Cho J, Leighl NB, Shepherd FA and Hope AJ: Utilization of prophylactic cranial irradiation in patients with limited stage small cell lung carcinoma. Cancer 116: 5694-5699, 2010.

13. Glantz MJ, Choy H and Yee L: Prophylactic cranial irradiation in small cell lung cancer: Rationale, results, and recommendations. Semin Oncol 24: 477-483, 1997.

14. Wolfson AH, Bae K, Komaki R, Meyers C, Movsas B, Le Pechoux C, Werner-Wasik M, Videtic GM, Garces YI and Choy H: Primary analysis of a phase II randomized trial Radiation Therapy Oncology Group (RTOG) 0212: Impact of different total doses and schedules of prophylactic cranial irradiation on chronic neurotoxicity and quality of life for patients with limited-disease small-cell lung cancer. Int J Radiat Oncol Biol Phys 81: 77-84, 2011.

15. Arriagada R, Spielmann M, Koscielny S, Le Chevalier T, Delozier T, Ducourtieux M, Tursz T and Hill C: Patterns of failure in a randomized trial of adjuvant chemotherapy in postmenopausal patients with early breast cancer treated with tamoxifen. Ann Oncol 13: 1378-1386, 2002.

16. Patel S, Macdonald OK and Suntharalingam M: Evaluation of the use of prophylactic cranial irradiation in small cell lung cancer. Cancer 115: 842-850, 2009.

17. Takada M, Fukuoka M, Kawahara M, Sugiura T, Yokoyama A, Yokota S, Nishiwaki Y, Watanabe K, Noda K, Tamura T, et al: Phase III study of concurrent versus sequential thoracic radiotherapy in combination with cisplatin and etoposide for limited-stage small-cell lung cancer: Results of the Japan Clinica Oncology Group Study 9104. J Clin Oncol 20: 3054-3060, 2002.

18. Gregor A, Drings P, Burghouts J, Postmus PE, Morgan D, Sahmoud T, Kirkpatrick A, Dalesio O and Giaccone $G$ : Randomized trial of alternating versus sequential radiotherapy/chemotherapy in limited-disease patients with small-cell lung cancer: A European Organization for Research and Treatment of Cancer Lung Cancer Cooperative Group Study. J Clin Oncol 15: 2840-2849, 1997.

19. Lebeau B, Urban T, Bréchot JM, Paillotin D, Vincent J, Leclerc P, Meekel P, L'Her P, Lebas FX and Chastang C: A randomized clinical trial comparing concurrent and alternating thoracic irradiation for patients with limited small cell lung carcinoma. "Petites Cellules" Group. Cancer 86: 1480-1487, 1999.

20. Chen AB, Neville BA, Sher DJ, Chen K and Schrag D: Survival outcomes after radiation therapy for stage III non-small-cell lung cancer after adoption of computed tomography-based simulation. J Clin Oncol 29: 2305-2311, 2011.
21. Rosen ST, Makuch RW, Lichter AS, Ihde DC, Matthews MJ, Minna JD, Glatstein E and Bunn PA Jr: Role of prophylactic cranial irradiation in prevention of central nervous system metastases in small cell lung cancer. Potential benefit restricted to patients with complete response. Am J Med 74: 615-624, 1983.

22. De Ruysscher D, Pijls-Johannesma M, Vansteenkiste J, Kester A, Rutten I and Lambin P: Systematic review and meta-analysis of randomised, controlled trials of the timing of chest radiotherapy in patients with limited-stage, small-cell lung cancer. Ann Oncol 17: 543-552, 2006.

23. Ahles TA, Silberfarb PM, Herndon J II, Maurer LH, Kornblith AB, Aisner J, Perry MC, Eaton WL, Zacharski LL, Green MR and Holland JC: Psychologic and neuropsychologic functioning of patients with limited small-cell lung cancer treated with chemotherapy and radiation therapy with or without warfarin: A study by the Cancer and Leukemia Group B. J Clin Oncol 16: 1954-1960, 1998

24. Fonseca R, O'Neill BP, Foote RL, Grill JP, Sloan JA and Frytak S: Cerebral toxicity in patients treated for small cell carcinoma of the lung. Mayo Clin Proc 74: 461-465, 1999.

25. Ball DL and Matthews JP: Prophylactic Cranial Irradiation: More Questions Than Answers. Semin Radiat Oncol 5: 61-68, 1995.

26. Ramlov A, Tietze A, Khalil AA and Knap MM: Prophylactic cranial irradiation in patients with small cell lung cancer. A retrospective study of recurrence, survival and morbidity. Lung Cancer 77: 561-566, 2012.

27. Schild SE, Foster NR, Meyers JP, Ross HJ, Stella PJ, Garces YI, Olivier KR, Molina JR, Past LR and Adjei AA; North Central Cancer Treatment Group: Prophylactic cranial irradiation in small-cell lung cancer: Findings from a North Central Cancer Treatment Group Pooled Analysis. Ann Oncol 23: 2919-2924, 2012.

28. van den Bent MJ: The role of chemotherapy in brain metastases. Eur J Cancer 39: 2114-2120, 2003.

29. Goldstraw P, Crowley J, Chansky K, Giroux DJ, Groome PA, Rami-Porta R, Postmus PE, Rusch V and Sobin L; International Association for the Study of Lung Cancer International Staging Committee; Participating Institutions: The IASLC Lung Cancer Staging Project: proposals for the revision of the TNM stage groupings in the forthcoming (seventh) edition of the TNM Classification of malignant tumours. J Thorac Oncol 2: 706-714, 2007. 